\title{
OVEREXPRESSION OF SUGARCANE SUCROSE TRANSPORT 1 (SoSUT1) GENE INCREASES RICE YIELD
}

\author{
Cesha Ananda Putri*1, 2), Bambang Soegiharto ${ }^{2}$, and Parawita Dewanti ${ }^{2}$ \\ ${ }^{1}$ Post Graduated Program for Agronomy, Faculty of Agriculture, University of Jember, Indonesia \\ ${ }^{2}$ CDAST (Center for Development of Advanced Science Technology), University of Jember, Indonesia
}

\begin{abstract}
The growth and development of plants are determined by photosynthesis, which ultimately results in sucrose. Sucrose is synthesized in the source then translocated to all parts of the plant (sink). The translocation process of sucrose from source to sink is controlled by sucrose protein called sucrose transporter. SoSUT1 is a gene that encodes a sucrose transporter 1 (SUT1) protein in sugarcane. Rice transformation with the SoSUT1 causes overexpression SUT, which is expected to increase the translocation of sucrose into the seed of rice plants. This research was conducted by introducing SoSUT1 in rice plants Inpari 14 SS. Transformation using Agrobacterium tumefaciens vector in apical bud explant Indica rice cv. Inpari 14 SS results in 26 events positive rice contains genes SoSUT1. This study aims to elucidate the inheritance of transgene in the next generation and to characterize its effect on the morphology and the yields of a subsequent generation. The study is conducted by planting the seeds of T1 and T2 plants in media containing Hygromycin and using PCR analysis for further analysis. As the results, from 26 events on the T1 plant, only 3 events of T3 plants were confirmed on the T3 plant. The overexpression of the SoSUT1 gene could increase the number of tillers, the number of productive tillers, panicle length, and panicle exit length, also increasing the number of spherical grains, reducing the number of empty grains and increasing the weight of 1000 grains.
\end{abstract}

Keywords: Rice, Sucrose, Sucrose Transporter, Transgenic Plant

* Corresponding author

CDAST (Center for Development of Advanced Science of Agriculture)

Jl. Kalimantan no 37, Kampus Tegal Boto, Jember, Indonesia

Phone and fax: (0331) 321825

E-mail: cesha.putri83@gmail.com

\section{Introduction}

Food is an obvious fundamental need of the world population, bolstering human activities. Rice (Oryza sativa L.) is a staple food in several countries, particularly in Indonesia. Many strategies are used for increasing domestic rice productivity, one of them through biotechnology. The development of biotechnology to increase crop productivity through genetic engineering has been widely applied in rice (Rahmawati, 2006). Increased rice productivity can be achieved by a producing a superior variety that has its own added value, one of which is through gene transformation.

Genetic transformation is the process of integrating exogenous DNA into the germline of whole organisms so that it is inherited in the subsequent generation. Saccharum officinarum sucrose transporter (SoSUT1) is a gene cloned from sugarcane, encoding a sucrose transporter.
Sucrose transporter is a protein that facilitates the process of translocating sucrose from source to sink (Rae et al., 2005). Sucrose synthesis in rice, particularly in the source will be transported to the sink which is used for energy sources during plant growth and plant development (Campbell et al., 2002). The overexpression of the SUT gene on the pea plant was able to increase the rate of sucrose accumulation in its storage organs (Rosche. $\mathrm{E}$, et al., 2002). On the other hand, the inhibition of SUT1 expression in potato plants using antisense has an effect on fresh weight during the early stages of tuber development (Khun, et al., 2003). SUT protein has been widely studied in almost all plants, such as tomatoes (Hackel, et al., 2006), sugar cane, and rice (Aoko, et al., 2003).

The success of gene transformation requires further testing and selection to obtain transgenic rice, containing SoSUT1. Also, the success of 
the transformation and the stability of transgenic expression can be confirmed by the analysis of the genotype and phenotype of the transgenic plant. Gilbert et al., (2009) suggested that the first generation of genetically modified (T1), still had heterogeneous properties. Moreover, according to Christou et al., (1992), one of the obstacles in assembling transgenic plant is the problem with inheritance to nextgeneration caused by unstable integration of the target gene into the chromosome host. Therefore, it is necessary to examine the subsequent generation and genetically stable plants.

The transgenic plant genotypes were analyzed by detecting the presence of target genes in the transgenic plant, while plant phenotypes were analyzed through the agronomic value and the yield. This study aims to determine the physiological characteristic and agronomic value of transgenic rice, and also to detect the productivity of transgenic rice in the third generation.

\section{Materials and Methods}

\section{Plant Materials}

The seedlings of rice cv. Inpari 14 with SoSUT1 overexpression and rice cv. Inpari 14 (wildtype) that used in this study were germinated by separating from their husks, sterilized using sodium hypochlorite $(\mathrm{NaOCl})$ $5.25 \%$ for $1 \mathrm{~min}$, rinsed with sterile distilled water and then aerated 1 hour in the sterile incubator.

The seedling in this study will be carried out until the third generation, so the number of events to be used is adjusted based on the selection results. In the third generation, agronomic measurements will be taken and the average results were statistically analyzed from 3 replications with 5 plants per event using Dunnett's test and t-test at $\mathrm{p} \leq 0.05$.

\section{Cloning and Transformation}

The SoSUT1 was isolated from sugarcane and constructed into vector $p A C T$ which contained rice actin promoters and hptII (hygromycin-phospo

transferase) markers as selectable markers to obtained pACT-SoSUT1. The vector was then transformed into Agrobacterium tumefaciens (A. tumefaciens) strain GV3101. The A. tumefaciens that harboring $p A C T-S o S U T 1$ was cultured in $50 \mathrm{ml}$ liquid YEP containing antibiotics (rifampicin $100 \mathrm{mgL}-1$, kanamycin $50 \mathrm{mgL}-1$, and streptomycin $30 \mathrm{mgL}-1$ ) until reach population density of OD $600=0.5-1$. To improve the transformation efficiency, 100 mgL-1 Acetosyringone was added into the cultured of A. tumefaciens before it used for the transformation of apical rice buds.

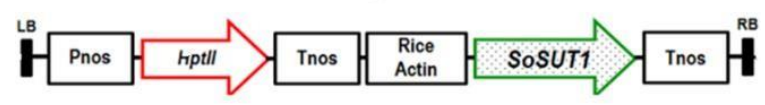

Figure 1. Construction of T-DNA plasmid pActSoSUT1. LB: left border, RB: right border, P-Nos: promoter of nopaline synthetase, hptII: hygromycin phosphor transferase gene, T-Nos: terminator nopaline synthetase, Promoter of rice actin, SoSUT1: Saccharum officinarum sucrose transporter (Sugiharto et al. 2008)

For explants preparation, the apical shoots were punched at the base of the lower stem using sterile needles. The explants were subsequently transferred into co-cultivation media (MS medium modified +100 mgL-1 acetate) for 1 day at $28^{\circ} \mathrm{C}$ under the desired conditions. The subculture was carried out in elimination media (MS + cefotaxime $500 \mathrm{mgL}^{-}$ ${ }^{1}$ ), incubated for 7 days in bright conditions. Stages of elimination were 5 times, plants that passed were selected and acclimatized. Leaves from transgenic rice that have been 30 days, taken for genome isolated to confirm the presence of SoSUT1 gene. Plants that have passed screening will be used for further analyses.

\section{Selection of Transgenic Plant}

Approximately 20 seeds of rice from each event in generation 1 (T1), generation 2 (T2) generation 3 (T3), and wildtype (WT) were selected and grown in a culture bottle containing MS media, containing $25 \mathrm{ppm}$ hygromycin. Especially for WT was cultured in the selection media and media without antibiotics. The method of selection was conducted according to Harrison et al. (2006) method, in which the seeds were planted in the selection medium and placed at $40^{\circ} \mathrm{C}$ for 4 days in dark condition. After the shoots grew, the culture bottles are placed in the growth chamber room with 16 to 8 hours for light and dark. Furthermore, the seeds that successfully germinated and survived in selection medium 
(grow healthy with the good condition) will be acclimatized in the greenhouse, and the phenotypes are observed during this stage.

\section{PCR and RT-PCR}

Genomic DNA was isolated from $500 \mathrm{mg}$ of rice leaf to confirm the presence of the SoSUT1 gene in transgenic rice (Zheng et al., 1991). The existence of the SoSUT1 gene were analyzed by polymerase chain reaction (PCR) analysis using primer hptII-F: 5'-CCG CAA GGAATC GGT CAA TA-3' dan hptII-R: 5'CCC AAG CTG CAT CGA AA -3' and the

sequence size is $\pm 490 \mathrm{bp}$. The PCR product was separated by electrophoresis in 1\% agarose gel, and visualized under UV light.

RT-PCR was performed as an expression analysis by detecting the SoSUT1 gene transcript. Frozen sugarcane leaves were weighed at $0.5 \mathrm{~g}$ and ground using liquid nitrogen, then isolated using a kit for RNA isolation (Tiagen, Beijing, China). The RNA content was measured with a NanoVue spectrophotometer (GE Healthcare, USA), then $1 \mu \mathrm{g}$ of total RNA was converted into cDNA using RT and an oligo-dT primer (Bio-Rad, USA). The first-strand cDNA was used for quantified the relative expression level of the SoSUT1 gene. The actin expression was used as the reference expression gene. The PCR products were run on a $1 \%$ agarose gel and visualized with GelDoc (Major Science, USA).

\section{Western Blotting}

Protein samples were obtained from the SUT1 leaf extraction of transgenic rice. Approximately $30 \mu \mathrm{g}$ proteins added to buffer loading, then denatured at $100^{\prime} \mathrm{C}$ for 3 minutes. Rice protein was separated using SDS-PAGE and electro-transferred to a nitrocellulose membrane. The membrane was immersed in $4 \%$ skim milk in 30 minutes at room temperature. The proteins were incubated with the specific antibody I (SUT1 specific polyclonal antibody) in 5\% skim milk in a TBS (Tris-Buffer Saline) solution for 3 hours at room temperature and subjected to three $5 \mathrm{~min}$ rinses in a TBS solution. The membrane was then incubated with the specific antibody II (Goat Anti-Rabbit IgGG Phosphatase Conjugated) for 1 hour at room temperature, and subjected to three 5 minutes rinses in a TBS solution. Staining process to check the transfer results using 100 $\mu 1 \mathrm{BCIP}$ and $50 \mu \mathrm{l} \mathrm{NBT}$, dissolved in the alkaline buffer then exposed with X-ray films.
The images were scanned and the intensity of each band was captured using a gel imaging system. The intensity of each band was standardized as a percentage of the total intensity and the results were referred to as a relative volume that represents the relative expression abundance of the gene in the samples tested. The relative expression abundance was used to evaluate protein expression stability.

\section{Morphological Analysis}

The analysis of morphological was conducted when the plant was in 30 days before planting by measuring plant height and counting the number of tillers. Later on, the productive tillers and the panicle's length were counted. Furthermore, the number of grains and empty grains in plants including 1000 grains weight per plant using the analytical scale of Preciza ES1200C.

\section{Results}

\section{Confirmation of Plasmid Construct}

Confirmation of the pAct-SoSUT1 plasmid construct in A. tumefaciens, strain GV 3101 is needed to detect the vector that has been inserted into the SoSUT1 target gene. Based on PCR analysis using hptII as a marker gene, with a DNA length of $490 \mathrm{bp}$, the results visualized in $1 \%$ agarose gel showed a $490 \mathrm{bp}$ DNA band (figure 2b). Based on this confirmation result, the colony (A. tumefaciens strain GV 3101) confirmed to carry the SoSUT1 target gene was selected for rice transformation.

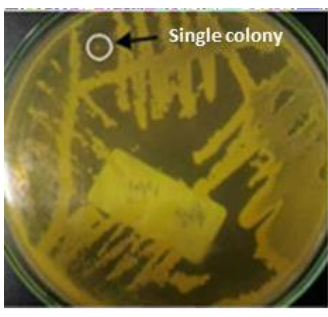

a.

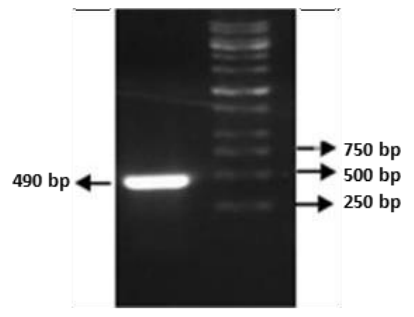

b.
Figure 2. (a) Single colonies on solid YEP media, (b) agarose $1 \%$ electrophoresis gel plasmid pActSoSUT1 DNA A. tumefaciens strain GV 3101 using F / R primers; (A) hptII, (B) DNA marker

\section{Rice Transformation With SoSUT1 Gene}

Explants with optimal transformation were found in 4-day old SS Inpari rice sprouts (Figure 3a). The transformation began by plant 
infection with $A$. tumefaciens carrying plasmid construct. Rice sprouts were punched using a small needle for 5-7 times on the base of shoots and roots parts, and put into liquid YEP media containing bacterial colonies and acetosyringone. Infected explants are then planted on co-cultivation media (figure $3 \mathrm{c}$ ).
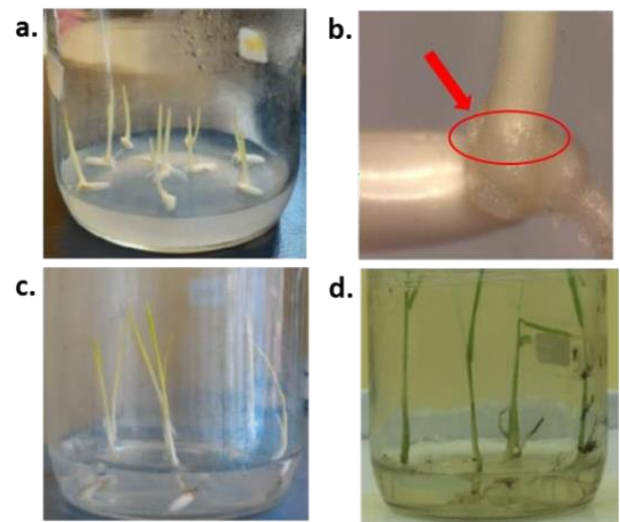

Figure 3. (a.) 4 days old Inpari 14 rice sprouts (b) Basal stems and roots treated (c) Explants planted in co-cultivation media, and (d) Plants on elimination media on $7^{\text {th }}$ day

At the co-cultivation stage, explants and $A$. tumefaciens were grown together at $28^{\circ} \mathrm{C}$ in dark conditions for 2 days. Explants that have gone through the co-cultivation stage were subcultured into elimination media containing 500 mgL-1 cefotaxime to eliminate $A$. tumefaciens.

\section{Confirmation of The Gene SoSUT1}

The in-vitro selection process is a step to characterize putative transformed rice seeds, taken before the confirmation process. The rice seeds containing SoSUT1 gene were planted in hygromycin medium. The seeds which not contained selective genes have stunted growth as shown in figure $4 a$, in other hand the seeds contained selective gene will not inhibited as in figure $4 \mathrm{~b}$. The seeds have passed the selection process will be acclimatized and planted in a greenhouse.

The selection process in each generation obtained a different number of plants. The first selection process for transgenic $\mathrm{T} 1$ rice resulted in 26 events. All events from T1 were selected to obtain T2 plants, and 11 events were GMO rice. After getting T2 plants next selection to get T3 plants, and get 3 events. All events that have been produced as a whole through the same process (acclimatization, planting in the greenhouse), and through PCR confirmation.

a.
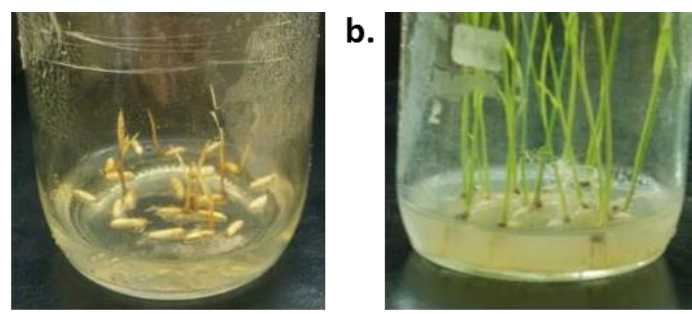

c.

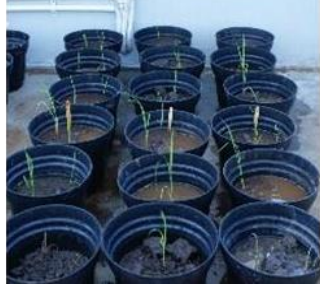

d.

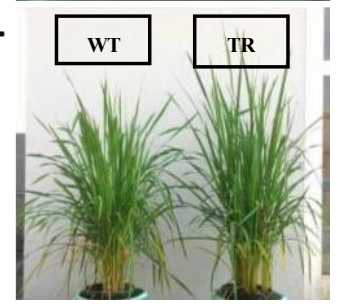

Figure 4. (a) Chlorosis in rice plants in selection media, (b) Rice plants that survived pass through media selection, (c) Acclimatization and (d) 1,5 month old plants. (WT: wildtype; TR: Transgenic).

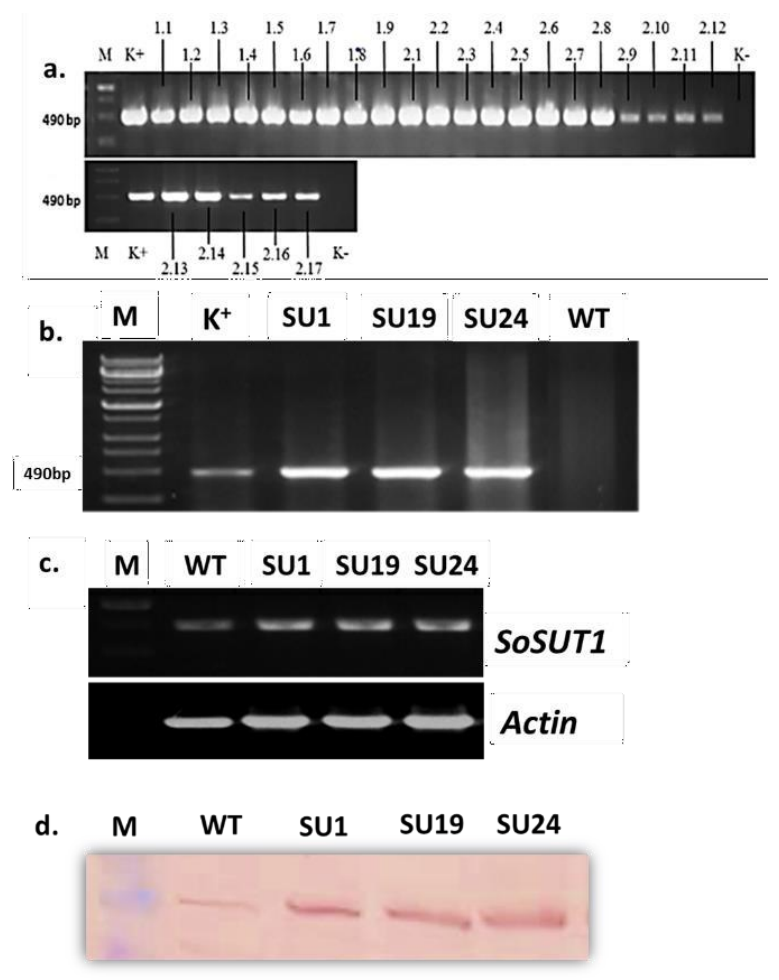

Figure 5. DNA electrophoresis results in $1 \%$ agarose gel from PCR using F / R hptII primers on DNA templates; (a) PCR results of T1, (b) and T3.

(c) RT-PCR results using SUT and actin primers, (d) SUT1 protein blots of third-generation rice plants (T3). (WT: wildtype) 
The figures (5a, and 5b) show PCR results in the 1st and 3rd generation, while the results of the 2 nd generation PCR have been reported earlier (Putri et al, 2017). Positive PCR results of the plants containing the SoSUT1 gene were shown by the formation of $h p t I I$ bands with a size of \pm $490 \mathrm{bp}$. The formation of hptII bands \pm 490 bp showed that the SoSUT1 target gene is located in a T-DNA along with the hptII gene, a selectable marker has been inserted into the plant genome. Whereas the negative plants could not form DNA bands in that size as shown by the wildtype control.

The presence of SUT protein in transgenic rice was confirmed by qualitative and compared to the wild-type. The third transgenic plant overexpressing the SoSUT1 gene was analyzed in the transcription and translation level to find out the content of SUT protein. RT-PCR was done using SUT1 primers to qualitatively analyzed gene expression at the transcription level in 3rd generation of transgenic rice. The difference in the increase in gene expression can be seen from the thickness of the DNA band visualized using RT-PCR. Figure 5c shows the results of visualization using Actin primers, this is used to show that the concentration of mRNA used to see the expression of the SoSUT1 gene between samples is the same. The actin gene ( $\beta$-Actin) is used as an internal control because it is a housekeeping gene that can equate the level of gene expression or mRNA in different samples (Li et al., 2010). The results of PCR visualization (Figure $5 \mathrm{c}$ ) showed an increase in the expression of the SoSUT1 gene at the level of transcription in 3rd generation transgenic rice compared to wild-type. Based on this, it can be stated that the overexpression process of the SoSUT1 gene in transgenic rice correlates to an increase in the number of mRNAs transcribed. Figure 5d shows that SUT1 protein is expressed in wild-type and overexpression of SoSUT1, this shows that rice does have SUT1 protein (endogenous). Based on the results of western blot analysis on transgenic rice SoSUT1 showed a thicker SUT1 protein band when compared to wild-type. The presence of thicker SUT1 protein bands is expressed as an increase in protein content which is thought to be due to overexpression of the SUT1 gene where there is an addition of SUT1 (exogenous). SoSUT1 gene that is transformed in rice can be expressed at the translational level is estimated to also form overexpression of SUT1 protein in the next generation so that the increase in SUT1 protein content in transgenic rice is expected to increase translocation and accumulation of sucrose in storage organs.

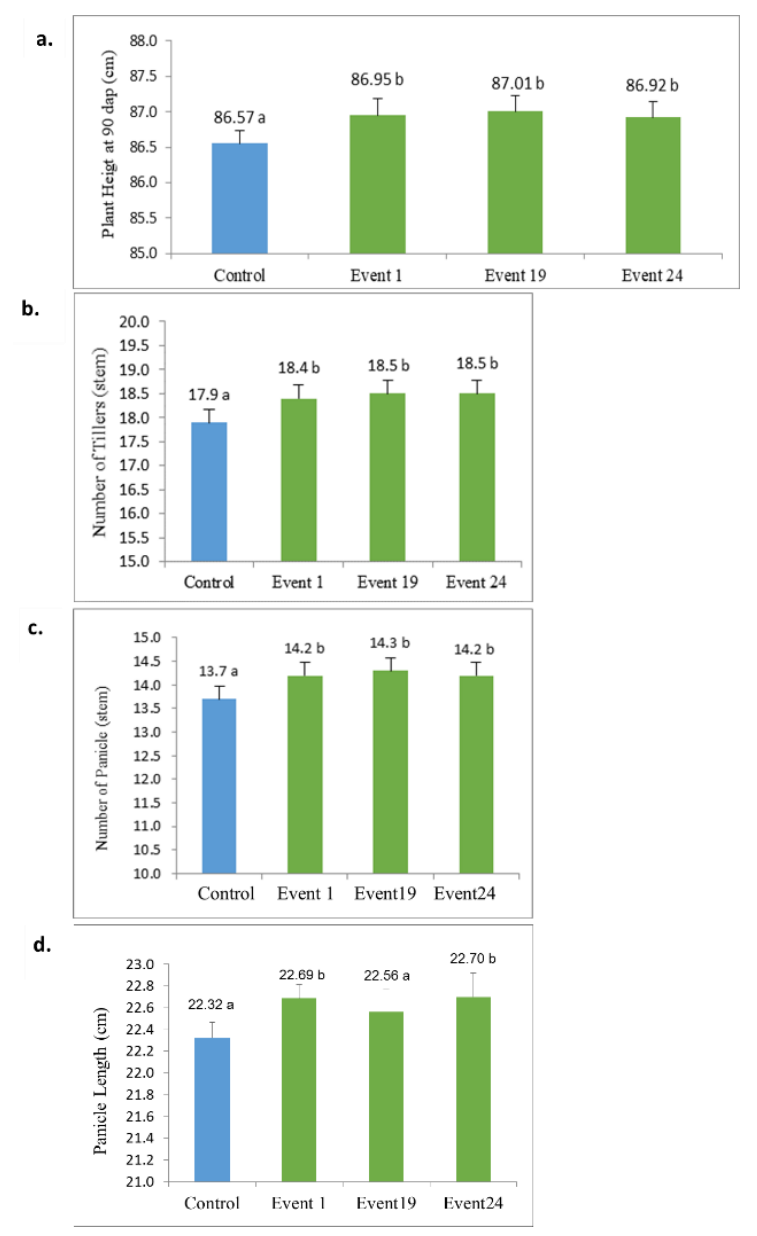

Figure 6. Morphological characters of $P R G$ rice plants. (a) Plant height, (b) Number of tillers, (c) Number of Panicle, and (d) Panicles Length. Error bar represents \pm SD of 5 replications. Number followed by the same letters indicate no real difference in the Dunnet 5\% test.

\section{Effect of SoSUT1 Overexpression on The Growth and Development of Rice Plants}

The growth of the plant was observed, including plant height, number of tillers, number of productive tillers, and panicle's length. The variable of plant height is showed significant differences between the transgenic rice and wild-type. Through the observation of the plant height, there was the highest average 
in the event $19(87.01 \mathrm{~cm})$ (fig.6a). The number of tillers in transgenic rice events 19 and 24 had the same average of 18.5 stems. (figure. $6 b$ ). The observation of the number productive tillers variable on transgenic rice in the event 19 had an average of 14.3 panicles which is the highest among the plants. Meanwhile, in event 1 and 24 were obtained productive tillers of 14.2 panicles (fig. 6c).

Based on Dunnet analysis in the event 19, 24 , and wild-type were shown insignificant differences (fig.6d). Panicle length showed a significantly different analysis of variance between transgenic rice and wild type, event 24 had the longest average at $22.70 \mathrm{~cm}$. Furthermore, the result of Dunnet analysis in the panicle length variable in the event 19 on transgenic rice and the wild-type showed no significant difference.

\section{Effects of SoSUT1 Overexpression on Rice Yield}

The yield variable on plants observed was grain per panicle, empty grain per panicle, and 1000 grains weight per panicle. The number of grains showed significant differences between the transgenic rice and the wild-type. Based on the observation of grain yields, the event 24 obtained about 106.47 grains which has real difference, compared to the wild-type. For the empty grain variable, there were significant differences between transgenic rice and the wild-type; event 1 had the highest grain number (28.05) while event 24 had the lowest (16.9) number among the plants (figure 7a).

In the observed variable of 1000 grain weight measurement, the results of variance analysis were significantly different between transgenic rice plants and wild-type plants. The heaviest weight of 1000 grains in event 19 is 26.05 gr. Dunnet test results with a weight of 1000 grains indicate that event 1 and wildtype were not significantly different. The total weight grains parameter of rice showed a significant difference between transgenic rice and wild type. The results of the heaviest grain weight at event 19 are 28.89 grams. Dunnet analysis of total grain weight, in event 24 shows that there were no significant differences with wildtype (figure $7 b$ ).
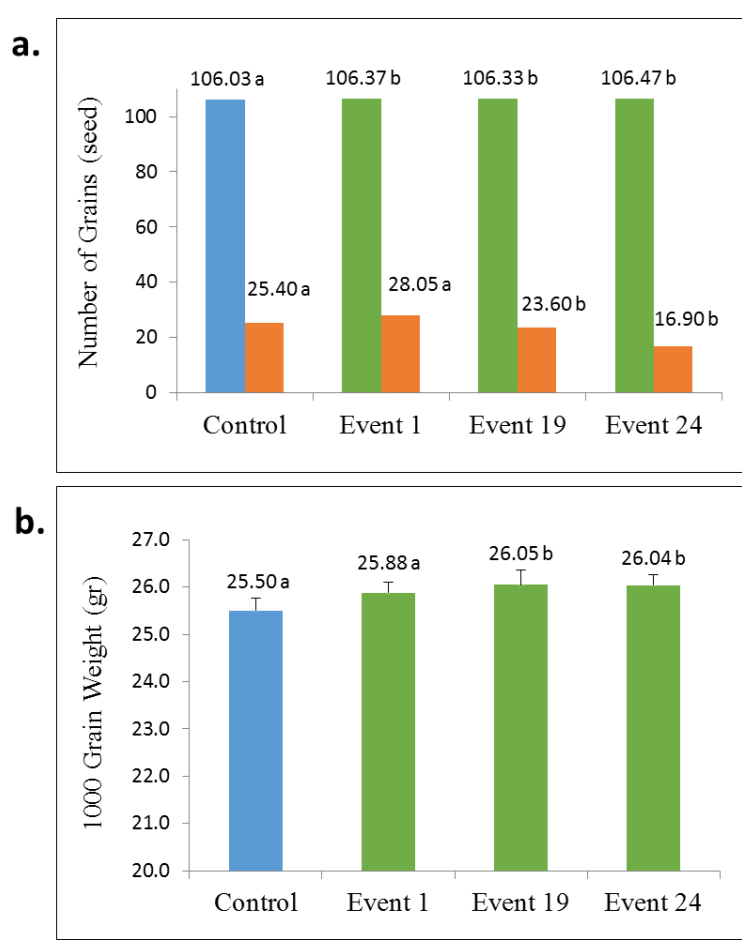

Figure 7. Rice grain yield, (a) Amount of rice grain (green and blue bar) and empty grain (orange bar),

(b) Weight of 1000 grains. Error bar represents \pm SD of 5 replications. Number followed by the same letters indicate no real difference in the Dunnet 5\% test.

\section{Dicussions}

Sucrose is the final product of assimilation carbon (C) in the process of photosynthesis (Kim et al., 2000). Sucrose is translocated from the source via phloem to the storage (sink) to support plant growth and development, accumulated on large amount in plant tissue as a storage (Campbell et al, 2002). In the process of sucrose translocation from the source to the sink, it is supported by protein transporter which is located in the plasma membrane and encoded by the sut gene. SUT affects the distribution and accumulation of sucrose in plants (Rae et al., 2000).

Based on DNA visualization result, overexpressed SUT does not always positively correlate with DNA fragments appearance, although it appears in plants $\mathrm{T} 1$ and $\mathrm{T} 2$, it cannot be visualized in the T3 plant (third generation). There is a decrease in the number of plant occurrences that appear in the DNA visualization from $\mathrm{T} 1$ to $\mathrm{T} 3$ plants. The decrease in the amount of visualization can be assumed that the SoSUT1 gene in T1 and T2 
plants are still heterozygous due to unstable insertion. However, there are some plant occurrences where DNA fragments still appear from generations of plants T1 to T3, this can be assumed that the SoSUT1 gene has been inserted correctly (stable) so that plants can be called homozygous. A stable transgenic organism occurs when the transgene is integrated into genomes and could be inherited into the next generation (Christou, et al., 1992). The appearance of protein target from transgenic rice in the $\mathrm{T} 3$ as observed on a western blot can be affected by many factors such as mRNA transferred, the initiation of transcription, the post-modified regulation, and the protein degradation. The high protein content is indicated by the accumulation of gene expression, SUT1 endogeneity, and SUT1 exogenous, which known as the overexpression gene.

Plant growth and development can be evaluated from their vegetative phase. It can be measured from plant height and the number of tillers. In measuring plant height, the presence of expressed SoSUT1 affects transgenic plant height. Sucrose in plants will be hydrolyzed into glucose and fructose. The simple sugars (glucose and fructose) are used in the formation of hexose. In the plant development phase, hexose will be used for cell division and extension (Weschke et al. 2003).

The sucrose from leaves will be transferred during the development of plant tillers. The plant tillers are an important part of the rice in which it becomes a major place of photosynthesis result during the vegetative phase and the early plant reproduction phase. According to the Ohashi (2018), the low level of sucrose transported by SUT from leaves during the plant growth may cause a slackening of the plant tillers formation.

In the pre-generative period, the effect of sut gene can be shown from the panicle and the tillers formation. Before the plant exerts out their panicle, there are a panicle insertion stage (the former stage) and a booting stage (the latter stage) which are included in the early generative phase and known as a critical phase, determining the grain yield. SUT1 protein expression in the early stages of the generative phase indicates the high need for sucrose in the reproductive parts of the plant, generally, sucrose is used by plants in the seed formation phase. (Ishimaru et al., 2005).
Rice productivity was determined by the yield of grain produced, while the high and low quality of rice plant products was influenced by the amount of rice grain (content) and at least empty grain. If one panicle shows mostly empty grain it will affect the lower productivity of the plant. The amount of grain is determined by a large number of productive tillers and the age of the flowering plants, where pollination will succeed in producing the rice grains. The process of filling rice coming from sucrose is brought by SUT1 protein and then converted into starch. In the process of filling rice grains, SoSUT1 plays a role in the transfer of sucrose to aleuron cells in seed endosperm and also plays a role in accumulating starch in seeds (Saalbach et al, 2014). Sucrose acts as a signaling transition in the regulation of storage, hormonal, and metabolism of seeds.

Rice productivity is influenced by the total number of grains, productive tillers, and the weight of 1000 grains. According to Chaturvedi et al., (2017), the grain filling stage requires a high photosynthesis rate because it can increase the grain weight up to $60 \%$. Through a high rate of photosynthesis, it is expected that more sucrose is formed so that the transportation of sucrose by SoSUT1 in plants also increases.

The results obtained from protein analysis show an increase in SUT1 protein expression, albeit some factors may also affect this level of transcription and translation such as mRNA amount, mRNA transport, mRNA stability, mRNA splicing process, and DNA availability (Grierson et al., 1988). Similar to the expression at the transcription level, at the translation level gene expression is influenced by several factors including the short length of the mRNA to be translated, the initiation of transcription, the regulation of post-translation (modification), and protein degradation. Some researchers claim that the correlation between gene expression (mRNA) and the level of translation is very low. High protein concentration allows high concentrations of mRNA as well. However, with low mRNA levels, it is also possible to have high protein levels. This can occur if the protein directly affects the expression process so that there is negative feedback which causes downregulation of mRNA expression (Grierson et al., 1988). 


\section{Conclusions}

Rice overexpression from the SoSUT1 gene decreased the number of events in the selection process from 26 events at $\mathrm{T} 1$ to 3 events at $\mathrm{T} 3$. The 3 positive confirmed events are event 1.19, and 24 . Growth and yield observation variables on T3 generation plants (total number of tillers, number of productive tillers, panicle length, grains per panicle, the weight of 1000 grains), on SoSUT1 rice plants, get higher values than wild types.This research still needs further research, so it can be known whether SoSUT1 overexpression rice can be developed or not.

\section{Acknowledgements}

This research was partly funded by a research collaboration between the Japan International Research Center for Agricultural Science (JIRCAS), Japan and the Research Center for Molecular Biology, University of Jember, Indonesia. (2008-2013)

\section{Reference}

Campbell, N.A., J.B. Reece and L.G. Mithcell. (2002). Biologi Jilid 1. Terjemahan oleh Rahayu. Jakarta: Erlangga.

Christou, P., P. Vain., A. Kohli., M. Leech., J. Oard and S. Linscombe. (1992). Introduction of Multiple Genes Into Elite Rice Varieties. Evaluation of Transgene Stability, Gene Expression and Field Performance of Herbicide. Resistant Transgenic Plant. Annal of Botany. Vol 77: 223-235.

Chaturvedi, A.K., Bahuguna, R.N., Pal. M., and Jagadish, S.V.K. (2017). High Temperature Stress During Flowering and Grain Filling Offsets Beneficial Impact of Elevated $\mathrm{CO} 2$ on Assimilate Partitioning and Sink Strengh in Rice. Scientific Report. Vol 7: 8227

Gilbert. R.A., N.C. Glynn, J.C. Comstock, and M.J.Davis. (2009). Agronomic Performance and Genetic Characterization of Sugarcane Transformed for Resistance to Sugarcane Yellow Leaf Virus. Field Crops Reasearch. 111:39:46

Grierson et al., (1988). Regulation of Differential Gene Expression during Plant Development. Plant Molecular Biology.

Harrison, S.J., Mott, E.K., Parsley, K., Aspinall, S.,Gray, J.C. \& Cottage, A. (2006). A rapid and robust method of identifying transformed Arabidopsis thaliana seedlings following floral dip transformation. Plant Methods 2(1): 19.
Ishimaru, K., Kashiwagi, T., Hirotou, N dan Madoka, Y. (2005). Identification and Physiological Analyses of a Locus for Rice Yield Potential Across the Genetic Back Ground. Journal Experimental Botany. Vol 56(420); 2745-2753.

Kim, J.Y., A. Mahe, J. Brangeon, \& J.L. Prioul (2000) A Maize Vacuolar Invertase, IVR2, is Induced by Water Stress. Organ/tissue Specificity and Diurnal Modulation of Expression. Plant Physiol. 124: 71-84.

Ohashi. M., Ishiyama. K., Kusano. M., Fukushima. A., Kojima. S., Hayakawa. T., and Yamaya. T. (2018). Reduction in sucrose contents by downregulation of fructose-1,6- bisphosphatase 2 causes tiller outgrowth cessation in rice mutants lacking glutamine synthetase1;2. Springer Rice Journal. Vol 11:65

Rae AL., JM perroux, CPL. Grof, (2005). Sucrose Partitioning Between Vascular Bundles and Storage Parenchyma in the Sugarcane Stem. A Potensial Role for the ShSUT1 Sucrose Transporter. Planta $220: 817-825$.

Rahmawati, S. (2006). Status Perkembangan Perbaikan Sifat Genetik Padi Menggunakan Transformasi Agrobacterium. Jurnal AgroBiogen. Vol. 2 (1): 36-44.

Rosche, E., Blackmore, D., Tegeder. M., Richardson, T., Schroeder, H., Higgins, T.J., Frommer, W.B., Offler, C.E., and Patrick, J.W. (2002). Seed-Specific Overexpression of a Potato Sucrose Transporter Increases Sucrose Uptake and Growth Ratesof Developing Pea Cotyledons. The Plant Journal. Vol. 30(2): 165-175.

Sambrook, J.,E.F. Fritsch dan T. Maniatis. (1989). Molecular Cloning : $A$ laboratory Manual. $2^{\text {nd }}$ Edition. USA: Cold Spring Harbor Laboratory Press.

Sugiharto, B., Slameto dan P. Dewanti. (2008). "Peningkatan Produksi Gula melalui Overekspresi Gen untuk SPS dan SUT pada Tanaman Tebu". Tidak Diterbitkan. Laporan Hibah kompetensi. Jember : Lembaga Penelitian Universitas jember.

Saalbach. I., Mora-Ramírez. I., Weichert. N., Andersch. F., Guild. G., Wieser. H., 
Koehler. P., Stangoulis. J., Kumlehn. J., Weschke. W., and Weber. H. (2014). Increased grain yield and micronutrient concentration in transgenic winter wheat by ectopic expression of a barley sucrose transporter. Journal of Cereal Science. XXX: 1-7

Towbin.A., Staehelin. T., and Gordon. J. (1979). Electrophoretic Transfer of Proteins from Polyacrylamide Gel to Nitrocellulose Sheets: Procedurs and Some Application. Proc NaH Acad Sci. vol 76: 4350-4354

Weschke W, Panitz R, Gubatz S, Wang Q, Radchuk R, Weber H dan Wobus U. (2003). The Role of Invertses and Hexose
Transporters in Controlling Sugar Ratios in Maternal and Filial Tissues of Barley Caryopses During Early Development. Plant Journal; 33:395-411.

Zheng, K., Huang, N., Bennet P., and Khush G. S. (1995). PCR Based Marker Assisted Selection in Rice Breeding. IRRI Discussion Paper Series No 12. 